\title{
Professor Hatsujiro Hashimoto: My Great Mentor as a Pioneer of Electron Microscopy
}

\author{
Yoshio Bando ${ }^{1,2}$ \\ 1. International Center for Materials Nanoarchitectonics (WPI-MANA), National Institute for Materials \\ Science (NIMS), Tsukuba, Japan. \\ 2. Australian Institute of Innovative Materials (AIIM), University of Wollongong (UOW), North \\ Wollongong, Australia.
}

Professor Hatsujiro Hashimoto died on April 15, 2017 at the age of 95. As one of his students, I am delighted to introduce his great accomplishments and personality. As a pioneer of electron microscopy, he has led the world for about 50 years. After the Second World War, when research parts were extremely scarce, he made his own hand-made electron diffraction equipment in 1948. After that, in 1952, he produced a universal electron diffraction microscope and succeeded in observing both electron diffraction patterns and electron microscope images (Fig. 1). The defect image observed in the molybdenum oxide thin film corresponded to the image of dislocation found in 1956 three years later.

He was very skilled in making equipment and developed new electron microscopes one after another. In 1966, he completed an electron microscopy equipped with a high-temperature gas reaction stage and succeeded in-situ observation of needle-like crystal growth processes (Fig. 2). He also greatly contributed to the development of high-resolution electron microscopes and succeeded in observing a single atom of thorium in 1971 (Fig. 3). After that, he studied dynamic observations of lattice defects in various materials at an atomic level. In 1984, he developed a new $400 \mathrm{kV}$ high-resolution analytical electron microscope with JEOL, which turned out to be the basis of commercial success of its manufacturer.

As mentioned above, his main achievements [1-8] are 1) Development and application of an universal electron diffraction microscope, 2) Development of an electron microscope equipped with elevated temperature gas reaction and in situ study of crystal growth, 3) Observation of a single Th atom in the dark-field image, 4) Development and application of 400kV analytical electron microscopes and others. These achievements were high in originality and other researchers couldn't follow.

When he was a professor at Kyoto Technical University, I belonged to his laboratory for 2 years during my master course. I got my desk at a corner of his office. Fortunately, I could receive his guidance every day. He taught me that it is useless to give up and told me to challenge as many times as possible. I still remember being told to look at an image with "the eyes of the heart", the mental eye during electron microscope observation. During my master program in 1970-1972, I studied the superstructure formed by the crystallization of silica glass. I presented my results at the International conference on Crystallography [9]. It was my first experience to make such a presentation.

He was also a rare researcher with diverse abilities. He was good at watercolor painting. When travelling, he always made sketches. Besides, he demonstrated multicultural talents such as calligraphy, Noh play, geology, sports (boat) and others. I am very sure he has enjoyed his whole life very much.

I am very grateful for many years under his guidance and express my deepest condolence. 
References:

[1] H. Hashimoto, Hyomen Gijyutu 59 (2008), p. 2.

[2] H. Hashimoto, Proc. of the Asian Science Seminar (1997), p. 25.

[3] H. Hashimoto and K. Tanaka, Proc. of the First Regional Conference in Asia and Oceania, Tokyo (1956), p.292.

[4] H. Hashimoto, A. Howie and M.J. Whelan, Phil. Mag. 5 (1960), p. 946.

[5] H. Hashimoto, A. Howie and M.J. Whelan, P. Roy. Soc. A 2691 (1962), p. 80.

[6] H. Hashimoto et al, J. Cryst. Growth 7 (1970), p. 113.

[7] H. Hashimoto et al, Jpn. J. Appl. Phys. 10 (1971), p. 1115.

[8] H. Hashimoto et al, J. Electron Microsc. 22 (1973), p. 123.

[9] Y. Bando and H. Hashimoto, Proc. Int. Conf. Crystallography, Kyoto (1972), p. 124.

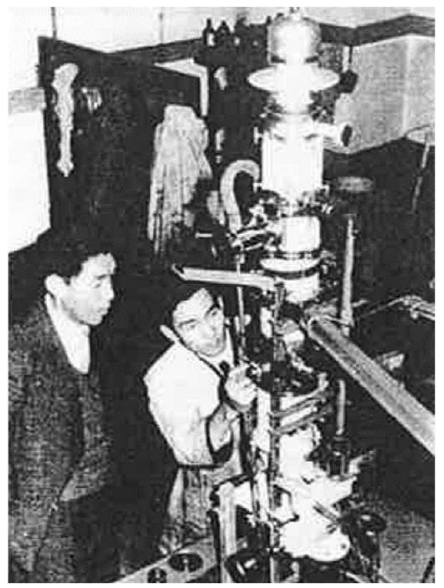
Figure 1. Development of
universal electron diffraction in 1953.

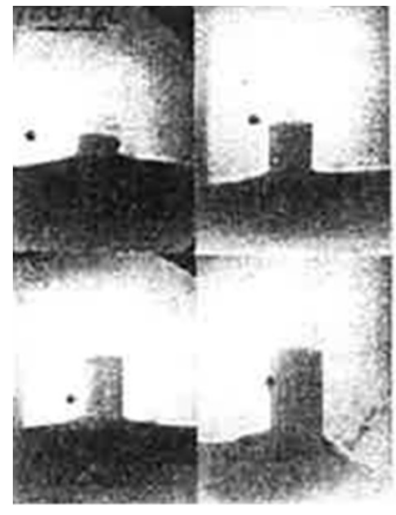

(a)

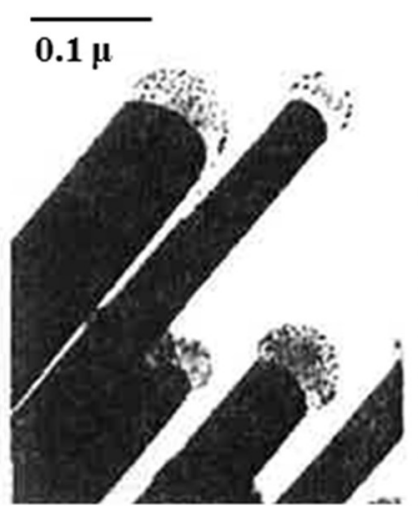

(b)

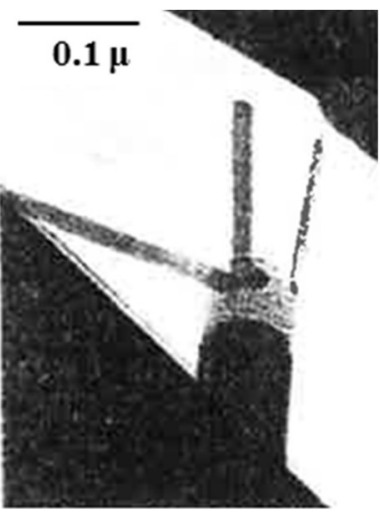

(c)

Figure 2. Direct observation of crystal growth of tungsten oxide needles. A molten oxide drop formed at the top of the needle and the needle grows from the drop (a-c).

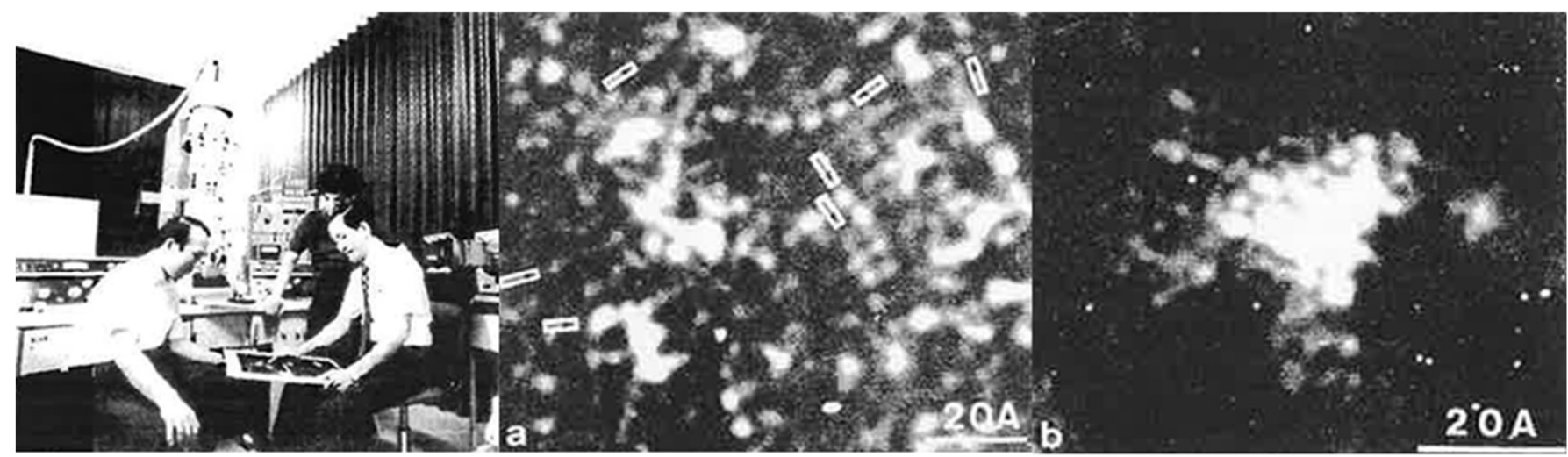

(a)

(b)

(c)

Figure 3. (a) Collaborators of Professor Hashimoto: Dr. A. Kumao (left) and Dr. H. Endoh (middle) at Kyoto Technical University in 1971. (b) Dark-field image of Th-pyromelitate molecules (arrows). (c) Dark-field image of a $\mathrm{ThO}_{2}$ single crystal. 